\title{
Effect of Nursing Intervention Guidelines on Nurses' Role, Patients' Needs, and Visual Problems Post Cataract Surgery
}

\author{
Nadia Mohamed Taha ${ }^{1}$, Nahla Ahmed Abd Elaziz ${ }^{2}$ \\ ${ }^{1}$ Medical-Surgical Nursing Faculty of Nursing at Zagazig University, Zagazig, Egypt \\ ${ }^{2}$ Community Health Nursing at Ain Shams University, Cairo, Egypt
}

Email address:

dr_nadya_mohamed@yahoo.com (N. M. Taha)

To cite this article:

Nadia Mohamed Taha, Nahla Ahmed Abd Elaziz. Effect of Nursing Intervention Guidelines on Nurses' Role, Patients' Needs, and Visual Problems Post Cataract Surgery. American Journal of Nursing Science. Vol. 4, No. 5, 2015, pp. 261-269. doi: 10.11648/j.ajns.20150405.13

\begin{abstract}
In Egypt, cataract is the major cause of blindness of the population aged 65 years or older. Inadequate postoperative nursing care may lead to serious complications for the patient with cataract surgery. The aim of this study was to evaluate the effect of the use of nursing guidelines on nurses' knowledge and practices and on their achievement of patients' needs post cataract surgery. This quasi-experimental pre-post assessment study was carried out on 34 nurses working at the outpatient clinics and ophthalmology departments in El Ramad Hospital, Rod El Farag, Cairo, affiliated to Ministry of Health and 34 patients undergoing cataract surgery in the setting. Data collection tools were a self-administered questionnaire and an observation checklist. The researcher developed nursing guidelines based on analysis of the data collected in the assessment phase to provide nurses with guides for care of cataract patients after surgery. The evaluation of the guidelines' effects on nurses' knowledge and practice, and consequently on patients' needs was carried out immediately after implementation (posttest), and 3 months after (follow-up). The results showed statistically significant improvements in nurses' knowledge and practice at the post and follow-up tests $(\mathrm{p}<0.001)$, with statistically significant strong positive correlation $(\mathrm{r}=0.714)$ between them. Also, there were statistically significant improvements in all areas of patient needs after implementation $(\mathrm{p}<0.001)$. In multivariate analysis, the intervention was a statistically significant independent positive predictor of the improvement in nurses' knowledge and practice, and of patients' needs. In conclusion, implementing nursing guidelines for care of cataract patients after surgery is effective in inducing improvements in nurses' related knowledge and practice, which better achievement of patients' needs. It is recommended that these guidelines be used in similar settings. Further research is proposed to investigate the effect of the implementation of these guidelines on decreasing the incidence of complications after the surgical technique.
\end{abstract}

Keywords: Cataract, Postoperative, Nursing, Guidelines, Knowledge, Practice

\section{Introduction}

Cataract, defined as loss of optical uniformity of the crystalline lens, develops gradually extending from minimal changes of original transparency of the lens to total opacity (WHO, 2013), leading to impairment of patient's visual acuity to mere distinction between light and dark (Casparis. 2012). Since its prevalence increases with age, the world's population aging is associated with increasing incidence of cataract-induced visual dysfunction and blindness. Hence, it is now a global problem so that everyone in the nineties is affected (Randleman, 2014). It is estimated that more than $82.0 \%$ of all blindness occurring in individuals aged 50 and older is related to cataract (Abraham \& Condon 2006). In Egypt, the prevalence of low vision for all ages is $47.9 \%$ of the population aged 65 years, with cataract being the major cause of blindness (54.8\%) (Hegazy et al, 2012).

Cataract is closely associated with fair or poor health status, restricted activity, impaired driving ability, significant emotional distress, and reduced quality of life. Moreover, low vision can be a significant psychological stressor for the patient as well as family members (Polack et al, 2007). When the visual acuity declines to about 20/50, this affects the person's safety or quality of life so that 
cataract surgery is usually recommended (Miller, 2009). The cure for cataract is surgery to remove the natural lens and replace it with a new, artificial one. It is one of the safest and most successful procedures performed, but this is not equally available to all, and the surgery which is available does not produce equal outcomes. Readily available surgical services capable of delivering good vision rehabilitation must be acceptable and accessible to all in need, no matter what their circumstances (Trent \& Albright 2014).

A patient who needs to undergo cataract surgery must be evaluated in a thorough manner so as to establish the requirement, appropriateness, influential co-morbid conditions, expected surgical problems and benefits (Vincent \& Patalano, 2012). The nurses should assess the patient's basic needs and intervene to assist to meet these needs. According to the Department of Health, needs are the requirements of individuals to enable them to achieve, maintain or restore an acceptable level of social independence or quality of life (Mansfield et al, 2011). Hence, recognizing the needs of patients with cataract surgery and understanding their physiological, psychological, and spiritual needs are essential skills for the ophthalmic nurse who should incorporate them in the form of nursing intervention (Potter \&Perry, 2001). Inadequate postoperative nursing care may lead to serious complications for the patient with cataract surgery (Surrena, 2009). The purpose of the nursing guideline is to enhance the quality, safety, effectiveness and availability of care for patient with cataract, to evaluate the effectiveness and appropriateness of techniques of prevention, diagnosis, treatment and clinical management of the healthy adult patient with cataracts (ACOES, 2013).

\section{Significance of the Study}

Cataract is a significant and increasing global as well as local problem. According to Statistical Department Report at Zagazig University Hospital, the number of patients undergoing cataract surgery was approximately 3500 in 2010. This condition may affect patients' independence in self-care and performance of the activities of daily living (ADL), with consequently reduced quality of life (QoL). Nurses play an important role in all aspects of cataract surgery. The challenges are to prevent or delay the occurrence of problems, and promptly manage any which does occur. Hence, patient needs must be identified, perfected and delivered through nursing proper nursing interventions. A pertinent nursing care guideline would thus help the nurses in ophthalmology departments.

\subsection{Aim}

The aim of this study was to evaluate the effect of the use of nursing guidelines on nurses' knowledge and practices and on their achievement of patients' needs post cataract surgery. The research hypothesis was that the implementation of the nursing guidelines will lead to statistically significant improvements in nurses' related knowledge and practice, and this would lead to better achievement of patients' needs post cataract surgery.

\subsection{Conceptual Framework}

The theoretical framework that guided in this study was Maslow's hierarchy of needs is often portrayed in the shape of a pyramid with the largest, most fundamental levels of needs at the bottom and the need for self-actualization at the top (B- Needs (being) Higher needs and D- Needs Deficit Survival). Maslow called "deficiency needs" or "d-needs": esteem, friendship and love, security, and physical needs. If these "deficiency needs" are not met - with the exception of the most fundamental (physiological) need - there may not be a physical indication, but the individual will feel anxious and tense (psychological) need. Maslow's theory suggests that the most basic level of needs must be met before the individual will strongly desire (or focus motivation upon) the secondary or higher level needs. Maslow also coined the term "meta-motivation" to describe the motivation of people who go beyond the scope of the basic needs and strive for constant betterment (Steere, 1988). Maslow used the terms "physiological", "safety", "belongingness" and "love", "esteem", "self-actualization" and "selftranscendence" to describe the pattern that human motivations generally move through. The hierarchy remains a very popular framework in sociology research, management training and secondary and higher psychology instruction (Mittelman, 1991).

\section{Subjects and Methods}

Design and setting: The study used a quasi-experimental design with pre-post assessment. Nurses were evaluated at three time intervals: before the intervention, at its completion, and 3 months after completion, whereas the effect on patients' was assessed before and after implementation. The study was carried out at the outpatient clinics and ophthalmology departments in El Ramad Hospital, Rod El Farag, Cairo, affiliated to Ministry of Health

Participants: The study involved a group of nurses, and another group of patients. The nurses' group consisted of all (34) nurses working in the ophthalmology departments of the study settings who are dealing with cataract patients. This sample size was large enough to demonstrate an improvement from a baseline of $30 \%$ satisfactory knowledge or adequate practice to an expected level of $60 \%$ with $95 \%$ level of confidence. The patients' group included 34 patients undergoing cataract surgery in the study setting selected by convenience sampling before implementing the nursing guidelines. Patient with history of previous cataract surgery, those with mental disablements, and those who cannot communicate were excluded.

Tool of data collection: The researcher prepared three tools for data collection, namely a self-administered questionnaire and an observation checklist for nurse's 
knowledge and practice, and an interview questionnaire form for patients.

- Self-administered questionnaire for nurses: It was designed by the researcher in Arabic and based on literature review and content-validated through experts' opinions in medical-surgical nursing and in ophthalmology. It included a section for nurse's personal characteristics such as age, marital status, qualification, years of experience, and attending any training courses related to cataract surgery. The main aim of this tool was to assess nurse's knowledge before and after implementation of the guidelines. It consisted of 47 multiple choice questions (MCQ) covering 4 main areas: 1) Anatomy and physiology of the eye such as eye layers, orbit, cornea, crystalline lens, etc.; 2) Cataract disease such as definition, causes and risk factors, types, signs and symptoms, diagnosis, prevention, in addition to cataract surgery indications, most common techniques, and complications; 3) Nursing care after cataract surgery such as proper position after surgery, nurse role for relieving postoperative pain, prevention of infection, signs and symptoms on infected eye, diet to help healing, postoperative complications, etc.; 4) Predischarge instruction for patient and patient family regarding use of eye drops and ointment, wearing eye shield and protection of the eye, precautions to prevent infection, food regimen to reduce straining and constipation, exercise and avoiding heavy lifting, unusual symptoms, follow-up, etc. For knowledge scoring, a correct response was scored 1 and the incorrect zero. For each area of knowledge, the scores of the items were summed-up and the total divided by the number of the items, giving a mean score for the part. These scores were converted into a percent score. Knowledge was considered satisfactory if the percent score was $60 \%$ or more and unsatisfactory if less than $60 \%$.

- Observation checklist for nurses' practice: The researcher prepared this checklist to evaluate nurses' practice of the care provided to patients after cataract surgery before and after the guidelines. It was based on Bare and Smeltzer (2004), MeCann and Judith (2009), and Cooper et al (2009). It assessed nurse's practice while instilling eye drops (8 steps); applying ointment ( 7 steps); changing eye dressing (17 steps); performing eye care and infection control (12 steps); practice of measures for relieving postoperative pain (5 steps); using non-pharmacological methods to reduce pain such as relaxation massage (9 steps), tense $\&$ relax exercise (56 steps), deep breathing exercise ( 7 steps), touch support, image (12 steps), private place (8 steps); and psychological support and reassurance (4 steps). Each step was checked as done and not done, respectively scored as 1 or 0 . For each area, the scores of the items were summed-up and the total divided by the number of the items, giving a mean score for the part. These scores were converted into a percent score. The practice was considered adequate if the percent score was $60 \%$ or more and inadequate if less than $60 \%$.

- Patient Interview Questionnaire Sheet: The researcher prepared this sheet to assess patient's visual problems and needs after surgery. It included a section for patient's personal characteristics such as age, sex, marital status, occupation, level of education, smoking, income, etc. The second section assessed patient's visual problems after cataract surgery through 10 closed-end questions covering sudden/severe pain, persistent headache, redness, discharge, blurring, as well as difficulty to see TV, problems with driving, difficulty recognizing faces, etc. The total number of problems was calculated by simple summation. The third section assessed patient's needs: 1) Physical needs as nutrition needs (time for eating and drinking, following appropriate food regimen, provision of adequate nutrition, and meals from outside); sleep and rest in hospital (quiet room with good sanitation and clean environment, relieving pain and comfort after pain relief); Activities of Daily Living: time for performing activities (rate of movement, watching TV, driving, exposure to sun, and maximum weight for lifting), activity limitation in the first week (shaving chin, self-bathing, combing hair, and bending down), medications management (follow prescribed medication, eye dressing change, precautions of drug side effects). Psychological needs such as proper dealing from health team, response of nurse to patient requests, answering patient's questions, feeling of safety and security, etc.). 3) Pre-discharge instructions needs (follow-up visits, unusual signs and symptoms, sleep position, food regimen, medications and eye care, and permissible activities. For scoring, the achieved need was scored 1 and the unachieved 0 . For each area, the scores of the items were summed-up and means and standard deviations and medians were computed. The maximum total score is 37 , and a higher score indicates more achieved needs.

Pilot study: A pilot study was conducted on five patients and nurses from the setting to check the clarity, applicability, relevance and feasibility of the tools, to identify the difficulties that may be faced during the application, and to estimate the time needed to fill them in. Necessary modifications were done, and the patients and nurses who shared in the pilot study were not included in the main study sample. However, the pilot nurses were included in the nursing intervention but not in data analysis.

Administrative design and ethical considerations: To carry out this study, the necessary approvals were obtained from the Head of ophthalmology Department, and from the General Director of the El Ramad Hospital. Letters were issued to them from the Faculty of Nursing, Zagazig University explaining the aim of the study in order to obtain permission and cooperation. The study protocol was 
approved by competent committees. At the initial encounter with each patient or nurse, an oral consent was secured from each subject after being informed about the nature, purpose, procedures, and benefits of the study, and that participation is voluntary. Confidentiality and anonymity of any obtained information were ensured through coding all data. The researcher reassured participants that the data collected would be used only for the purpose of the study and to improve patients' health. No harm could be anticipated from any maneuver in the implementation of the study.

Fieldwork: The study was implemented through assessment, planning, implementation, and evaluation phases during the period from January 2013 to June 2014.

Assessment phase: Upon finalization of the tools and getting official permissions, the researchers started to recruit the samples according to eligibility criteria. The patients' needs were assessed using the pertinent tool. Then, the nurses' knowledge was assessed using the selfadministered questionnaire. This was followed by observing their practice with cataract patients in different shifts using the observation checklist.

Planning phase: Based on analysis of the collected data, and using pertinent literature, the researcher developed guidelines to teach nurses training guidelines for care of cataract patients after surgery. It covered knowledge regarding cataract, cataract surgery, and nursing care of patients after cataract surgery, pre-discharge instructions for patients and their families, and follow-up for postoperative cataract patients. The practical part covered training in the skills of instilling eye drops, ointment application, changing eye dressing, performing eye care and infection control, practice of measures for relieving postoperative cataract pain, using non-pharmacological methods to reduce postoperative cataract pain, in addition to psychological support and reassurance.

Implementation phase: The nursing intervention guideline was delivered to nurses in six sessions. The teaching/training methods involved questioning, discussions, as well as demonstration and re-demonstration. The teaching media included illustrative pictures, videotapes and handouts. Sessions took 45-60 minutes. The guidelines were designed and presented in Arabic language. At the beginning of the first session, an orientation to the health guideline and its purpose was presented. Each session started by a summary of what had been taught in the previous session and the objectives of the new one, taking into consideration the use of simple language to suit the level of nurses. The researcher used motivation and reinforcement during the educational sessions to enhance learning. A copy of the guidelines was offered for each nurse and patient to use it as future reference.

Evaluation phase: The evaluation of the guidelines' effects on nurses' knowledge and practice, and consequently on patients' need was carried out using the same assessment tools. Each nurse was evaluated immediately after implementation of the guidelines (post-test), and three months after implementation of the guidelines (follow-up), and these were compared to pre-test levels. For patients, the evaluation was done by comparing the assessment done after guidelines' implementation with the pre-guidelines visual problem and achievement of needs assessed at the outpatient surgery clinic at a follow-up visit.

Statistical analysis: Data entry and statistical analysis were done using SPSS 18.0 statistical software package. Quantitative continuous data were compared using the nonparametric Mann-Whitney test. Qualitative categorical variables were compared using chi-square or Fisher exact tests as appropriate. Spearman rank correlation was used for assessment of the inter-relationships among quantitative variables and ranked ones. In order to identify the independent predictors of nurses' knowledge and practice scores and of patients' visual problems and needs achievement multiple linear regression analysis was used after testing for linearity and homoscedasticity, and analysis of variance for the full regression models was done. Statistical significance was considered at $\mathrm{p}$-value $<0.05$.

\section{Results}

All nurses in the study sample were females, with age ranging between 24 and 45 years (Table 1a). The majority was married $(97.1 \%)$, and carried a diploma in nursing (94.1\%). Their total experience years ranged between 6 and 27 with median 15, whereas their experience in ophthalmology ranged between 1 and 27 years with median 8 years. Only $11.8 \%$ of the nurses reported having previously attended training courses.

Table 1. Socio-demographic characteristics of participants in the study sample $(n=34)$.

\begin{tabular}{|c|c|c|}
\hline & Frequency & Percent \\
\hline \multicolumn{3}{|l|}{ Age: } \\
\hline$<30$ & 20 & 58.8 \\
\hline $30+$ & 14 & 41.2 \\
\hline Range & $24.0-45.0$ & \\
\hline Mean \pm SD & $31.9 \pm 6.5$ & \\
\hline Median & 33 & \\
\hline \multicolumn{3}{|l|}{ Marital status: } \\
\hline Married & 33 & 97.1 \\
\hline Unmarried & 1 & 2.9 \\
\hline \multicolumn{3}{|l|}{ Nursing qualification: } \\
\hline Diploma & 32 & 94.1 \\
\hline Bachelor & 2 & 5.9 \\
\hline \multicolumn{3}{|l|}{ Experience years (total): } \\
\hline$<10$ & 15 & 44.1 \\
\hline $10+$ & 19 & 55.9 \\
\hline Range & $6.0-27.0$ & \\
\hline Mean \pm SD & $14.0 \pm 6.0$ & \\
\hline Median & 15.0 & \\
\hline \multicolumn{3}{|c|}{ Experience years (in ophthalmology): } \\
\hline$<10$ & 24 & 70.6 \\
\hline $10+$ & 10 & 29.4 \\
\hline Range & $1.0-27.0$ & \\
\hline Mean \pm SD & $9.7 \pm 6.2$ & \\
\hline Median & 8.0 & \\
\hline Attended training courses: & 4 & 11.8 \\
\hline
\end{tabular}


b) Patients

\begin{tabular}{lll}
\hline & Frequency & Percent \\
\hline Age: & & \\
$<60$ & 19 & 55.9 \\
$60+$ & 15 & 44.1 \\
Range & $33.0-73.0$ & \\
Mean \pm SD & $55.7 \pm 9.2$ & \\
Median & 59 & \\
Gender: & & \\
Male & 18 & 52.9 \\
Female & 16 & 47.1 \\
Marital status: & & \\
Married & 28 & 82.4 \\
Widow & 6 & 17.6 \\
Job status: & & \\
Unemployed & 26 & 76.5 \\
Working & 8 & 23.5 \\
Formal education: & & \\
No & 25 & 73.5 \\
Yes & 9 & 26.5 \\
Smoking & 8 & 23.5 \\
Sufficient income & 8 & 23.5 \\
\hline
\end{tabular}

As for patients (Table 1b), their age ranged between 33 and 73 years, with slightly more males $(52.9 \%)$. The majority was married $(82.4 \%)$, unemployed $(76.5 \% 0$, and had no formal education $(73.5 \%)$. Less than one-fourth of them were smoking (23.5\%) and had sufficient income (23.5\%).

Table 2 demonstrates generally low percentages of satisfactory knowledge before implementation of the guidelines. The least satisfactory knowledge was regarding the anatomy of the eye $(32.1 \%)$ and role of the nurse $(44.1 \%)$ for cataract patients. On the other hand, more than three quarters of the nurses $(79.4 \%)$ had satisfactory knowledge about cataract. At the post-guidelines phase, statistically significant improvements were noticed in nurses' knowledge, with all nurses having satisfactory knowledge in all areas $(\mathrm{p}<0.001)$. This improvement persisted during the follow-up period compared with baseline $(\mathrm{p}<0.001)$, with slight nonsignificant declines. The total satisfactory knowledge increased from $38.2 \%$ at baseline to $100 \%$ and $97.1 \%$ at the post and follow-up phases.

Similarly, the table indicates that none of the nurses had adequate practice in applying ointment, eye dressing using infection control, breathing and leg exercises, and nonpharmacologic pain relief before implementation of the guidelines. The post guidelines and follow-up phases showed statistically significant improvements in nurses' practices in all areas $(p<0.001)$. In total, none of the nurses had adequate practice, compared to $100 \%$ at both post and follow-up phases $(\mathrm{p}<0.001)$.

Concerning the visual problems and achievement of needs among cataract patients, Table 3 shows decreases in the median number of visual problems from 3.0 at the preguidelines phase to 2.0 at the post-guidelines phase; however, this decrease was not statistically significant. Meanwhile, the medians of the scores of needs achieved demonstrated statistically significant improvements in all areas after guidelines' implementation $(\mathrm{p}<0.001)$. The most prominent improvement were concerning performing activities of daily life (ADL), medications, and pre-discharge instructions. In total, the median score of achieved needs increased from 14.0 at the pre-guidelines phase to 34.0 at the post-guidelines phase $(\mathrm{p}<0.001)$.

The study findings revealed a statistically significant strong positive correlation $(\mathrm{r}=0.714)$ between nurses' scores of knowledge and practice (Table 4). Meanwhile, no statistically significant correlations could be shown between nurses' knowledge and practice scores from one side and any of their characteristics from the other side.

Table 2. Nurses' knowledge and practice throughout the intervention phases.

\begin{tabular}{|c|c|c|c|c|c|c|c|c|}
\hline & \multicolumn{6}{|c|}{ Time } & \multirow{3}{*}{$X^{2}$ (Pre-post) } & \multirow{3}{*}{$X^{2}$ (Pre-FU) } \\
\hline & \multicolumn{2}{|c|}{ Pre $(n=34)$} & \multicolumn{2}{|c|}{ Post $(n=34)$} & \multicolumn{2}{|c|}{ FU $(n=34)$} & & \\
\hline & No. & $\%$ & No. & $\%$ & No. & $\%$ & & \\
\hline \multicolumn{9}{|c|}{ Satisfactory knowledge $(60 \%+)$ about: } \\
\hline Eye anatomy & 11 & 32.1 & 34 & 100.0 & 33 & 97.1 & $34.76(<0.001 *)$ & $31.17(<0.001 *)$ \\
\hline Cataract & 27 & 79.4 & 34 & 100.0 & 33 & 97.1 & Fisher $(0.01 *)$ & Fisher $(0.054)$ \\
\hline Nursing care & 15 & 44.1 & 34 & 100.0 & 32 & 94.1 & $26.37(<0.001 *)$ & $19.91(<0.001 *)$ \\
\hline Discharge instructions & 16 & 47.1 & 34 & 100.0 & 33 & 97.1 & $24.48(<0.001 *)$ & $21.11(<0.001 *)$ \\
\hline Satisfactory & 13 & 38.2 & 34 & 100.0 & 33 & 97.1 & 30.38 & 26.88 \\
\hline Unsatisfactory & 21 & 61.8 & 0 & 0.0 & 1 & 2.9 & $(<0.001 *)$ & $\left(<0.001^{*}\right)$ \\
\hline \multicolumn{9}{|l|}{ Adequate practice $(60 \%+)$ of: } \\
\hline Instillation of eye drops & 9 & 26.5 & 34 & 100.0 & 34 & 100.0 & $39.53(<0.001 *)$ & $39.53(<0.001 *)$ \\
\hline Applying ointment & 0 & 0.0 & 34 & 100.0 & 34 & 100.0 & $68.00(<0.001 *)$ & $68.00(<0.001 *)$ \\
\hline Eye dressing & 0 & 0.0 & 34 & 100.0 & 34 & 100.0 & $68.00(<0.001 *)$ & $68.00(<0.001 *)$ \\
\hline Eye care & 1 & 2.9 & 34 & 100.0 & 34 & 100.0 & $64.11(<0.001 *)$ & $64.11(<0.001 *)$ \\
\hline Psychological support & 5 & 14.7 & 34 & 100.0 & 34 & 100.0 & $50.56(<0.001 *)$ & $50.56(<0.001 *)$ \\
\hline \multicolumn{9}{|l|}{ Total practice: } \\
\hline Adequate & 0 & 0.0 & 34 & 100.0 & 34 & 100.0 & 68.00 & 68.00 \\
\hline Inadequate & 34 & 100.0 & 0 & 0.0 & 0 & 0.0 & $(<0.001 *)$ & $(<0.001 *)$ \\
\hline
\end{tabular}

(*) Statistically significant at $\mathrm{p}<0.05$ 
Table 3. Total patients'visual problems and achievement of needs before and after the intervention.

\begin{tabular}{|c|c|c|c|c|c|c|}
\hline & \multicolumn{4}{|l|}{ Time } & \multirow{3}{*}{ Mann Whitney Test } & \multirow{3}{*}{ p-value } \\
\hline & \multicolumn{2}{|l|}{ Pre $(n=34)$} & \multicolumn{2}{|l|}{ Post $(n=34)$} & & \\
\hline & Mean \pm SD & Median & Mean \pm SD & Median & & \\
\hline $\begin{array}{l}\text { Number of visual problems } \\
\text { Needs achieved: }\end{array}$ & $3.6 \pm 2.1$ & 3.00 & $3.0 \pm 2.3$ & 2.00 & 1.96 & 0.16 \\
\hline Nutrition & $2.4 \pm 1.6$ & 2.00 & $4.7 \pm 0.4$ & 5.00 & 43.18 & $<0.001 *$ \\
\hline Sleeping and rest & $3.6 \pm 1.7$ & 4.00 & $5.8 \pm 0.4$ & 6.00 & 41.88 & $<0.001 *$ \\
\hline Performing ADL & $0.0 \pm 0.2$ & 0.00 & $3.4 \pm 0.8$ & 4.00 & 55.74 & $<0.001^{*}$ \\
\hline Activities first week & $1.1 \pm 0.9$ & 1.00 & $3.5 \pm 0.6$ & 3.50 & 47.57 & $<0.001^{*}$ \\
\hline Medication & $1.2 \pm 1.1$ & 1.00 & $4.1 \pm 1.5$ & 5.00 & 39.67 & $<0.001^{*}$ \\
\hline Psychological needs & $4.0 \pm 2.0$ & 4.50 & $5.5 \pm 1.0$ & 6.00 & 13.55 & $<0.001 *$ \\
\hline Pre-discharge instructions & $1.7 \pm 0.5$ & 2.00 & $5.9 \pm 0.3$ & 6.00 & 58.51 & $<0.001^{*}$ \\
\hline Total needs achieved & $14.0 \pm 4.5$ & 14.00 & $32.9 \pm 3.5$ & 34.00 & 50.52 & $<0.001^{*}$ \\
\hline
\end{tabular}

(*) Statistically significant at $\mathrm{p}<0.05$

Table 4. Correlation between nurses' knowledge and practice scores and their socio-demographic characteristics.

\begin{tabular}{lll}
\hline & \multicolumn{2}{l}{ Spearman's rank correlation coefficient } \\
\cline { 2 - 3 } & Knowledge scores & Practice scores \\
\hline Practice & $.714^{* *}$ & \\
Age & -0.06 & -0.10 \\
Qualification & -0.04 & 0.14 \\
Experience years (total) & -0.04 & -0.06 \\
Experience years (ophthalmology) & 0.04 & 0.05 \\
\hline
\end{tabular}

(**) Statistically significant at $\mathrm{p}<0.01$

Table 5. Best fitting multiple regression model for nurses'knowledge and practice scores.

\begin{tabular}{|c|c|c|c|c|c|c|c|}
\hline & \multicolumn{2}{|c|}{ Unstandardized Coefficients } & \multirow{2}{*}{$\begin{array}{l}\text { Standardized } \\
\text { Coefficients }\end{array}$} & \multirow{2}{*}{ t-test } & \multirow{2}{*}{ p-value } & \multicolumn{2}{|c|}{ 95\% Confidence Interval for B } \\
\hline & B & Std. Error & & & & Lower & Upper \\
\hline \multicolumn{8}{|c|}{ Knowledge score } \\
\hline Constant & 68.55 & 6.82 & & 10.06 & $<0.001$ & 55.02 & 82.07 \\
\hline Intervention & 13.87 & 1.48 & 0.68 & 9.39 & $<0.001$ & 10.93 & 16.8 \\
\hline Age & -0.38 & 0.19 & -0.15 & -2.02 & 0.047 & -0.76 & -0.01 \\
\hline \multicolumn{8}{|c|}{$\mathrm{r}$-square $=0.47$, Model ANOVA: $\mathrm{F}=46.10, \mathrm{p}<0.001$} \\
\hline \multicolumn{8}{|c|}{ Variables entered and excluded: qualification, experience, training } \\
\hline \multicolumn{8}{|l|}{ Practice score } \\
\hline Constant & -45.73 & 6.52 & & -7.01 & $<0.001$ & -58.67 & -32.79 \\
\hline Intervention & 19.05 & 2.05 & 0.49 & 9.31 & $<0.001$ & 14.99 & 23.11 \\
\hline $\begin{array}{l}\text { Knowledge } \\
\text { score }\end{array}$ & 0.97 & 0.1 & 0.51 & 9.68 & $<0.001$ & 0.77 & 1.17 \\
\hline \multicolumn{8}{|c|}{$\mathrm{r}$-square $=0.85$, Model ANOVA: $\mathrm{F}=280.65, \mathrm{p}<0.001$} \\
\hline Variables ent & and excl & ualification, $\mathrm{e}$ & ce, training & & & & \\
\hline
\end{tabular}

Table 6. Best fitting multiple regression model for patients'number of visual problems and needs achievement scores.

\begin{tabular}{|c|c|c|c|c|c|c|c|}
\hline & \multirow{2}{*}{\multicolumn{2}{|c|}{$\begin{array}{l}\text { Unstandardized } \\
\text { Coefficients }\end{array}$}} & \multirow{3}{*}{$\begin{array}{l}\text { Standardized } \\
\text { Coefficients } \\
\end{array}$} & \multirow{3}{*}{ t-test } & \multirow{3}{*}{ p-value } & \multicolumn{2}{|c|}{ 95\% Confidence } \\
\hline & & & & & & \multicolumn{2}{|c|}{ Interval for B } \\
\hline & B & Std. Error & & & & Lower & Upper \\
\hline \multicolumn{8}{|l|}{ Visual problems } \\
\hline Constant & -6.03 & 2.1 & & -2.87 & 0.006 & -10.23 & -1.83 \\
\hline Age & 0.13 & 0.04 & 0.54 & 3.71 & $<0.001$ & 0.06 & 0.2 \\
\hline Sufficient income & 3.11 & 0.75 & 0.6 & 4.17 & $<0.001$ & 1.62 & 4.59 \\
\hline \multicolumn{8}{|c|}{$\mathrm{r}$-square $=0.33$, Model ANOVA: $\mathrm{F}=9 ., 35, \mathrm{p}<0.001$} \\
\hline \multirow{2}{*}{\multicolumn{8}{|c|}{$\begin{array}{l}\text { Variables entered and excluded: sex, marital status, job, education, chronic disease, intervention, previous eye disease/surgery } \\
\text { Needs achievement }\end{array}$}} \\
\hline & & & & & & & \\
\hline Constant & 3.08 & 4.03 & & 0.76 & 0.448 & -4.98 & 11.14 \\
\hline Intervention & 19.2 & 0.94 & 0.94 & 20.33 & $<0.001$ & 17.31 & 21.09 \\
\hline Age & -0.17 & 0.06 & -0.15 & -2.63 & 0.011 & -0.3 & -0.04 \\
\hline Job status & -2.27 & 1.36 & -0.09 & -1.67 & 0.1 & -4.99 & 0.45 \\
\hline Visual problems & 0.45 & 0.22 & 0.1 & 2 & 0.05 & 0 & 0.89 \\
\hline
\end{tabular}


In multivariate analysis (Table 5), the intervention was identified as a statistically significant independent positive predictor of the improvement in nurses' knowledge while age was a negative predictor. The model explains $47 \%$ of the variation in the knowledge score. As for the practice score, the table illustrates that both the intervention and the knowledge score were its statistically significant independent positive predictors. The model explains $85 \%$ of the improvement in this score. On the other hand, nurses' qualification, years of experience, and previous training had no influence on their knowledge or practice scores.

Table 6 displays the best fitting multiple linear regression models for the visual problems and needs achievement for patients throughout intervention. It is evident that the statistically significant positive independent predictors of the changes in visual problems were patients' age and income. The model explains $33 \%$ of this change. As for the score of needs achieved, the intervention and the number of visual problems were its statistically significant positive independent predictors, whereas patients' age and job status were negative predictors. The intervention was the most influential as its standardized coefficient indicates. The model explains $86 \%$ of the improvement in the score of needs achievement. Other patient's characteristics such as sex, education, marital status and chronic disease had no influence on the visual problems and needs achievement.

\section{Discussion}

Cataract surgery is a process that can be safely performed even in outpatient clinics (Koolwijk et al, 2015). With the varied practices for cataract surgery and the increasing number of cases, there is room for better service organization in hospitals in terms of better staff preparation time to improve outcomes (Olali et al, 2010). The present study tested the hypothesis that the implementation of the nursing guidelines will lead to statistically significant improvements in nurses' related knowledge and practice, and this would lead to better achievement of patients' needs post cataract surgery. The findings generally lead to acceptance of this hypothesis given the shown improvements in nurses' knowledge and practice with consequent improvement in meeting the needs of the patients who had their cataract surgery.

According to the study findings, nurses' knowledge was generally low before implementation of the guidelines, particularly the knowledge of the anatomy of the eye and more importantly of the role of the nurse for cataract patients. The deficient knowledge about anatomy may not be as important as the lack of knowledge of the nurse role since this is the essence of their work, and without this knowledge they would not be able to provide the care needed. The finding is in agreement with Belal (2004) in study at Ain-Shams University Hospitals who reported that nurses' knowledge of the anatomy and physiology of the eye was unsatisfactory.
The implementation of the guidelines led to significant improvements in nurses' knowledge in all tested areas, and this was retained throughout the follow-up. This indicates the positive impact of the guidelines on nurses' knowledge, and this was further confirmed through multivariate analysis which identified the intervention as a significant independent positive predictor of the improvement in nurses' knowledge. A similar success of an intervention in improving nurses' knowledge about eye care was demonstrated in a study in Tanzania (Mafwiri et al, 2014). Thus, and in congruence with the revealed importance of the guidelines, Kearney et al (2006) recommended that nurses need to be aware of eye disease and conditions in older adults which should be standardized within their work environment through the use of protocols to ensure safety and therapeutic outcomes.

Meanwhile, nurses' age was identified as a negative predictor of their knowledge score, which means that the younger age nurses get higher benefits from the guidelines compared with older ones. This might be explained by the fact that younger age nurses are more eager to learn and can acquire knowledge easier than the older ones who may have forgotten the process of studying and learning anew.

The present study has also demonstrated a major deficiency in nurses' practice of post-operative care for cataract patients before implementation of the guidelines. It was a striking finding that none of them could adequately practice the application of eye ointment, eye dressing using infection control, and non-pharmacologic pain relief. This might be attributed to that these nurses may rely on their long experience years in their job, which extends to 27 years; thus, their practice is based on experience rather than on knowledge and evidence. Therefore, they might give no due attention to strict infection control procedures, and depend only on prescribed analgesics for pain relief. Hence, Tantawy (2004) stressed in a study at Ain-Shams University Hospitals that when the years of experience are increased, nurses have to learn more to improve their knowledge, and skills for patients.

In congruence with these foregoing current study findings, Ahmed (2007) in a study at Zagazig University Hospital reported that more than three quarters of the nurses performed eye care incorrectly. Also, Stollery et al (2008) emphasized the importance of aseptic technique when changing eye dressing, which was not followed by most nurses in the current study. Moreover, Mohamed (2008) revealed deficient practice among ophthalmic nurses in study at Ain-Shams University Hospitals, particularly regarding the provision of unplanned incomplete verbal instructions to patients at discharge. On the contrary, the role of nurses in pain relief after cataract surgery has been demonstrated with great success in Mayo clinic (Erie et al, 2011).

The nurses' practice after implementing guidelines demonstrated significant ameliorations, and this extended throughout the follow-up. The findings reflect the positive 
effect of the intervention, and this was again confirmed in the multivariate analysis which showed that the intervention as well as the knowledge score was significant independent positive predictors of the practice score, and they explained together almost all the improvement in this score. Thus, the practical training element of the intervention, in addition to the theoretical part was effective in modulating nurses' practice. Furthermore, a strong positive correlation was revealed between nurses' knowledge and practice scores, which again underscores the importance of the theoretical element of the guidelines. In agreement with this, Lin et al (2013) stressed that nurses should pay more attention to systemic evaluation of the patients, health education, and psychological guidance, which is the key to ensure the safety of patients. Thus, new trends based on improving nurses' knowledge through nursing care standards could enhance their knowledge and consequently improve their practice.

The improvement of nurses' knowledge and practice would be futile if it does not lead to better patient care and outcomes. According to the current study results, significant improvements were shown in the achievement of all patients' needs after guidelines' implementation compared with baseline. This is certainly a reflection of the amelioration of nurses' knowledge and practice. In fact, the multivariate analysis the intervention was the most influential positive predictor of the score of needs achievement. This is in line with the recommendation of human resource development for vision 2020 in developing countries which emphasized team building and ensuring available workers perform optimally rather than meeting the absolute numbers of some cadre, which does not guarantee improved output (Adepoju et al, 2011).

Meanwhile, patients' age and job status turned to be negative predictors of the score of patients' needs achievement. This means that the older patients and those having work had less achievement of their needs. The finding could be attributed to that older age patients' needs may be more than those of younger ones since they may suffer other health problems that need attention. As for the working patients, they might be more exigent in their needs given the importance of rapid cure to return to work. In line with this, Elsabagh (2012) in a study at Ain-Shams University Hospitals revealed a significant relation between the age and needs of the studied patient before and after cataract surgery. Also, Nirmalan et al (2005) in a study in Rural India shows a significant association between patients' visual problems and their job status.

On the contrary, although the number of visual problems among the patients of the present study decreased at the postguidelines phase, this decrease did not reach statistical significance. Moreover, the multivariate analysis demonstrated that patients' age and income was the significant positive predictor of the changes in visual problems and not the intervention. This is quite plausible since most of the postoperative problems of vision have a natural history of progress with time regardless the care provided.

\section{Conclusions and Recommendations}

In conclusion, implementing nursing guidelines for care of cataract patients after surgery is effective in inducing improvements in nurses' related knowledge and practice, which is a better achievement of patients' needs. Therefore, it is recommended that these guidelines be used in similar settings for confirmation of the results and for improvement of the guidelines. Further research is proposed to investigate the effect of the implementation of these guidelines on decreasing the incidence of complications after the surgical technique.

\section{References}

[1] Abraham A. G., and Condon N. G. (2006): The New Epidemiology of Cataract. Ophthalmol Clin J; 19(1): 415-425. Available at: www.unisinucartagena. edu.co

[2] Adepoju F. G., Ayanniyi A. A., Pam V., and Akanbi T. B. (2011): Human resource development for Vision 2020 in developing countries: a change from absolute numbers. Eur J Ophthalmol;21(6):820-5.

[3] Ahmed M. (2007): Assessment of Patients Needs, Nurses Role in Caring Children with Ophthalmic Disorder, Unpublished Master Thesis, Faculty of Nursing, Ain Shams University.

[4] Ahmed S. A. (2007): Study of Nurses Performance Regarding Infection Control for Patients with Central Venous Catheter, Unpublished Master Thesis, Faculty of Nursing Zagazig University.

[5] American College of Eye Surgeons (ACOES), (2013): "Guidelines for Cataract Practice" Ehttp://www.acesabes.org/guidelines_for_cataract_practice.htm Available at. $2 / 8 / 2013$ at $7.17 \mathrm{pm}$.

[6] Bare B. G., and Smeltzer S. C. (2004): Brunner and Suddarth Textbook of Medical Surgical Nursing. $10^{\text {th }}$ ed., Philadelphia: Lippincott Williams and Wilkins, Awolters Kluwer, p. 605.

[7] Belal S. A. (2004): Postoperative Self - Care Guide for Patient with Intraocular Surgery. Unpublished Master Thesis, Faculty of Nursing, Ain Shams University, p. 5430.

[8] Casparis H., Lindsley K., Kuo I., Sikder S., and Bressler N. (2012): Cataract surgery in people with age-related macular degeneration. The Cochrane Collaboration; 11(6): 35 - 9.

[9] Cooper A., Endacott R., and Jevon P. (2009): Clinical Nursing Skills Core and Advanced. $1^{\text {st }}$ ed. USA: Oxford University Press Co, p. 80

[10] Elsabagh NS. (2012): Patients Undergoing Laparoscopic Cholecystectomy: Needs Assessment, Unpublished Master Thesis, Faculty of Nursing, Ain Shams University.

[11] Erie A. J., McHugh R., Warner M., and Erie J. C. (2011): Model of anesthesia care that combines anesthesiologists and registered nurses during cataract surgery. J Cataract Refract Surg.;37(3):481-5.

[12] Hegazy S. M., Ragheb M. M., Elsayed N. O., and Rashad M. A. (2012): Health Needs Managements Among Patients Undergoing Day Case Cataract Surgery. Proposed protocol, life science Journal; 9(2): 1316-1327. Available at: http://www.lifesciencesite.com. 
[13] Kearney N., Richardson A., and Foubert J. (2006): Nursing patient's with eye disease: Principles and Practice. Philadelphia: Churchill Livingston El Sevier Co, pp. 393-399.

[14] Koolwijk J., Fick M., Selles C., Turgut G., Noordergraaf J. I., Tukkers F. S., and Noordergraaf G. J. (2015): Outpatient cataract surgery: incident and procedural risk analysis do not support current clinical ophthalmology guidelines. Ophthalmology.;122(2):281-7.

[15] Lin J., Fang X., and Wu S. (2013): The management pattern carried out in a cataract surgery day ward. Eye Sci.;28(2):79-83.

[16] Mafwiri M., Kisenge R., and Gilbert C. E. (2014): A pilot study to evaluate incorporating eye care for children into reproductive and child health services in Dar-es-Salaam, Tanzania: a historical comparison study. BMC Nurs.;13:15.

[17] Mansfield A., Nathanson V., Jayesinghe N., and Foyle G. (2011): The psychological and Social Needs of patients. British Medical Association; 26(4): 1-3. Available at: http://www.bma.org.uk/images/psychologicalsociaIneeds patients_tcm41

[18] MeCann S., and Judith A (2009): Lippincott's Nursing Procedures. $5^{\text {th }}$ ed., USA: Lippincott Williams \& Wilkins Wolter Kluwer Health, pp. 282-285.

[19] Miller C. (2009): Vision in Nursing for Wellness older Adults. $5^{\text {th }}$ ed., China: Lippincott Williams \& Willinks Co., p. 344

[20] Mittelman, W. (1991). "Maslow's study of self-actualization: A reinterpretation". Journal of Humanistic Psychology 31 (1): 114135. doi: $10.1177 / 0022167891311010$

[21] Mohamed Y. (2008): Effect of Educational Program on Nursing Performance in Ophthalmic Laser, Unpublished Doctoral Thesis, Faculty of Nursing, Ain Shams University.

[22] Nirmalan P. K., Tielscb J. M., and Robin A. L. (2005): Relation between Vision Impairment and Eye Disease to Vision - Specific Quality of Life and Function in Rural India. The Aravind Comprehensive Eye Survey, Aravind Medical Research Foundation; 46(7): 2308-2312.

[23] Olali C. A., Priya A., Gupta M., and Ahmed S. (2010):
Cataract surgery in the United Kingdom: a postal survey. Eur J Ophthalmol.;20(4):684-6.

[24] Polack S., Kuper H., Mathenge W., Fletcher A., and Fosrer A. (2007): Cataract Visual Impairment and Quality of Life in Kenya Population. BJ Opthalmol; 91(7): 927-932.Available at.www.ncbi.nlm.nih.gov/pubmed/17272387bjo.bmj. com/ content /91/7/927. pdfthtml.

[25] Potter P., and Perry A. (2001): Fundamental of Nursing. $5^{\text {th }}$ ed. USA: Mosby, pp. 1655-1657.

[26] Randleman J. (2014): Cataract Surgery, http://www.medicinenet.com/ cataract surgery /article.htm [Medically Reviewed by a Doctor on 1/30/2014] MedicineNet.com.

[27] Steere, B. F. (1988). Becoming an effective classroom manager: A resource for teachers.. Albany, NY: SUNY Press. ISBN 0-88706-620-8

[28] Stollery R., Shaw M., and Lee A. (2008): Ophthalmic Nursing. $3^{\text {rd }}$ ed., India: Black Well Co, p.15.

[29] Surrena H. (2009): Handbook for Brunner and Suddarth's Textbook of Medical Surgical Nursing, $10^{\text {th }}$ ed., Philadelphia: Lippincott Williams and Willinks, p. 214

[30] Tantawy N.M. (2004): Development of Nursing Care Standards for Emergency Surgical Patients, Unpublished Doctoral Thesis, Faculty of Nursing, Ain Shams University.

[31] Trent D., and Albright M. D.(2014): Patient Information For Before \& After Cataract Surgery About The Procedure, 89 E Wilson Bridge Rd, Worthington, OH 43085, 614 -401-9927 http://www.worthingtoneye.com/files/public/docs/ pre-postop-cataract-surgery-instructions.pdf 19/11/2014 at $6.18 \mathrm{pm}$

[32] Vincent J., and Patalano I. (2012): The Risks and Benefits of Cataract Surgery. Digital Journal of Ophthalmology; 3 (7): 23 5.

[33] World Health Organization (2013): Prevention of Blindness and Visual Impairment: Priority Eye Diseases, http://www.who.int/blindness/causes/ priority/en/index1.html [Accessed January 4, 2013]. 